\title{
Preschool Teachers' Perspectives about School Partnerships with the Family and Community Obstacles in Saudi Arabia
}

\author{
Najla Essa Albaiz \\ Early Childhood Education, Ph.D. \\ Assistant Professor \\ College of Education, King Saud University \\ Saudi Arabia
}

\begin{abstract}
The research explored preschool teachers' perspectives about the SPFC obstacles of school partnership with family and community (SPFC) in Riyadh City, Saudi Arabia. A purposeful sample of (12) teachers to explore their experiences with partnerships within three different social and economic areas. Thematic analysis was used to analyze teachers' responses and the analysis provided two main themes; partnership obstacles, and partnerships enhancement. The result provided different stories to show the need (or not) of specific practices. The interviews focused on teachers' experiences and highlighted many of the barriers that weakened the partnerships and emphasized the need to enhance these partnerships. This enhancement should be from different levels and parties, including but not limited to the teachers, coworkers, families, Ministry of Education (MoE), and the community.
\end{abstract}

Keywords: School-family partnerships, school-community partnerships, preschool education.

\section{Introduction}

A substantial body of research asserted that the SPFC is fundamental to students' achievement and development (Catone, Friedman, Potochnik, \& Thompson, 2014; Ishimaru, 2017; Leddy, 2019; Epstein et al., 2019). This is getting more importance with preschool years (3-6 year- old) because the families become essential component in preschoolers' transition from homes to the school environment (Walsh, Romo, and Jeon, 2018).Epstein (1992)built a model for studying the SPFC andher theoretical perspective of the overlapping influences showed that there are three different spheres (environments): the school, family, and community. These spheres can "be pushed together or be pulled apart by practices and interpersonal forces in each environment" (Epstein, 1992, p. 2). For example, the school and family spheres get closer if the teacher and a family member contact each other regularly. Research proved the validity of the model in improving children's development and reducing behavioral problems (Simon, 2001; Obeidat\& Al-Hassan, 2009; Puglisi, Hulme, Hamilton, and Snowling, 2017).

Even though literature gives such attention to benefits of the SPFC, the research documented obstacles impede the partnerships. Langdon \& Vesper (2000) indicated that the teachers believed the weak family involvement was a major problem that limited schoolwork improving. Some of the barriers are related to the parents such as time restrictions. The other barriers related to the teachers such as the lack of the knowledge and training needed to conduct successful the partnerships (Flynn, 2007). Schweiker-Mara, (2000) found that many teachers thought that collaboration with their students' families is not teachers' responsibilities. Epstein et al. (2009) added that school and family partnerships "rarely receives adequate attention from school, district, and state education leaders" (p. 40).

The Saudi Arabian preschool curriculum included some strategies to work with the children's families and involve the local community (Ministry of Education, 2014). Realizing the significance of the partnerships, the Saudi Vision 2030 (2016) developed the program IRTIGAA (means enhancement in Arabic). The program aimed to enhance the SPFC and according to the Organizational Guide of The School Partnership with the Family and Community, the program adopted Epstein's model (2019) for the partnership (Ministry of Education, 2019).The SPFC would increase after attention given by the schools and The SaudiMoE. The SPFC has been a sensitive issue in Saudi Arabia and the preschool is not included in the educational ladder or a prerequisite for first grade (elementary school) admission. Certainly, many families give less attention to children's participation in preschool activities and not all families and school personnel are aware of the importance of engaging parents in their children's education (Ghahwaji, 2007).

Alshanwani (2013) evaluated the Self Learning curriculum, the Saudi preschool official curriculum, and found that some essential elements disappeared, such as family contributions to their children's development and the parents' role in decision-making related to learning activities. Much research took the approach of exploring the reality of the 
implementation of SPFC in Saudi Arabia; yet, preschool teachers' perspectives about the obstacles impede practicing the partnership has not been discovered so far. The study results are important as they are in a line with the new MoE reformations as a response to the National Transformational Program 2020as a part of the Saudi Vision 2030. The program emphasizes the significant role of SPFC and encourages school to involve at least $80 \%$ of the families into different school activities. Preschool teachers' voices are of considerable significance. Bąk-Średnicka (2018) claimed that teachers' readiness to effectively engage children's families and the community depends on their perspective toward the partnerships. Thus, the purpose of this qualitative study was to answer these two questions:

1- What were preschool teachers' perspectives about the SPFC obstacles?

2- How would the preschool teachers improve the implementation of the SPFC?

\section{Literature Review:}

Several theorists described the importance of strong family-school ties in a child's development. Epstein et al. (2009) partnership's model includes the following six practices: (1) Parenting: The preschool supports parents to raise their roles at home. (2) Communicating: Adequate two-way communication occurs between the preschool and homes and vice versa about a child's development and school program. (3) Volunteering: The preschool offers a variety of volunteering opportunities suitable for families. (4) Learning at home: This provides opportunities for parents to be involved in their children's homework and other school activities. (5) Decision-making: The preschool works with the family unit as a team to make decisions related to the school and community. (6) Collaborating with the community. The preschool suggests community resources and facilities to the family and offers services for the community. Epstein et al. (2009) explained in the theory of overlapping spheres the main idea to create a family-like environment in schools, which welcomes all family structure and meets each child's needs. The school-like families can be created in the home environment that motivates students-children - to be creative and achieve better outcomes in school. Bronfenbrenner (1999), proposed in his ecological systems theory that dynamic relationships that have open, trusted lines of communication between the family and school are essential for the child's development. Yet, if the relationship breaks down between them, the child's growth will be affected negatively (Paquette and Ryan, 2001).

\subsection{SPFC in Saudi Arabia:}

Many efforts related to SPFC have been made recently in Saudi Arabia. As a part of the King Abdullah bin AbdulAziz's Public Education Development Project, in 2015, the Preschool Development Program created the Saudi Early Learning Standards (SELS) through collaborating with the NAEYC. Some of the statements that were used to build the SELS are (1) In order to develop educational goals and plans, it is important to be aware of each child's cultural context and encourage positive relationships with families, and (2) children learn better when their families are partners in the educational process (Tatweer, 2015). Another MoE project provides neighborhood clubs for children, their families, and community members. These clubs are held in school buildings and provide many activities and enrichment classes, such as physical education and sports, arts, and reading (Tatweer, 2015).

In 2019, MoE published The Organizational Guide for preschool and Nurseries. One of the subsections describes the work of the SPFC committee. The committee's goal is to encourage preschool personnel to collaborate with families and the community. The committee members are the school principals, school vice principal, two teachers, three students' mothers, and a member of the private sector. Some of the committee roles are to plan, investigate, and improve work fields with families and the community. Another goal is to train teachers, children, and their families to contribute through volunteer work.

\subsection{SPFC Obstacles:}

Families and teachers need to be informed of each other's needs and objectives toward pupils' educations. If not, teachers will lack information related to families' efforts at home that are relevant to their children's education and to what their future ambitions are for their children. On the other hand, families do not have knowledge of teachers' efforts or teaching plans to achieve educational goals. They also lack information about involvement opportunities. Also, the children themselves lack knowledge of their family's or teacher's goals. Communication among these three parties can fill in the blanks and unite the effort when each party understands the other's goals and works together to achieve these goals (Epstein \& Sanders, 2000).

Literature has been developed out of the broadly-based interest in investigating obstacles that impede from successfully implementing the partnership with the family and community. Epstein et al. (2019) emphasized that the communication should be mutual between school and home and between home and school. Yet, time restrictions, for example, may hinder effective communication between both parties (Ingram,Wolfe, \& Lieberman., 2007). In addition to time, many 
challenges associated with communication, including job commitments, feeling unwelcome based on cultural differences, and families' negative perceptions toward school communication, may impede the success of communication (Graham-Clay, 2005; Olmstead, 2012; Epstein et al., 2019).

Physical participation is not required, as technology partially solves this issue; the challenge here is not all parents have Internet connections or can afford smart devices, for many reasons (Graham-Clay, 2005). Olmstead (2012)investigated teachers' and parents' attitudes about school-home technological communication and found that it is more effective than traditional communication for both teachers' and parents' points of view, though the study also showed that a lack of network access was one of the obstacles to communication. The parents in the study indicated that classroom websites or email was more convenient for communicating updates regarding their children's educational or schoolbased activities.On the other hand, with critical situations, parents prefer in-person meetings with the teacher (Olmstead, 2012).

Even though decision-making practice, as one of the partnerships with the family activities, holds benefits for students' scholastic performance (Noguera, 2001), the research to assess the performance of this practice is not prolific (Detroit Community-Academic Urban Research Center, 2014). Simon (2001) found that about one third of the study sample, (330) public school principals, indicated they have not provided opportunities to engage parents in making decisions, which affected their students' academic performance and families' attitudes toward the schools.Sanders (2001) concentrated on his quantitative nationwide research on community roles in the activation SPFC model. The study investigated information from more than 400 American schools. The findings showed that inadequate time and absence of trained management were reported as obstacles to work with the community agencies. The school needed enough time to locate and communicate with community resources, which requires professional leadership.

In Saudi Arabia, previous research focused partially on obstacles to the implementation of SPFC related to the curriculum, teachers' lack of skills, or lack of community awareness. Alotaibi and Alswelem (2002) aimed to evaluate the Saudi early childhood goals. The researchers surveyed teachers from public and private schools and found that one if the barriers to the implementation of these goals was that preschool is not included as an educational ladder. The teachers in Alotaibi and Alswelem's (2002) study asserted that they suffered because of the community's low perception of preschool teachers' job. The teachers added that, regarding family-school collaboration, families were uncooperative in terms of home-based learning and undervalued the teachers' work and the role of preschool in children's lives. Albaiz's (2009) study investigated the achievement of the preschool goals and found that weaker parents' beliefs of the importance of preschool education affected the achievement of these goals. That highlights the need to raise parents' awareness about the importance of family involvement.

The teachers in Alghamdi's (2016) study admitted that family involvement at the preschool level is weak due to either families' personal choices or organizational restrictions imposed by higher authorities. According to Hakim (2012), preschool education faces many challenges that impede its success. The author listed the weak relationships between children's families and schools as the top challenge that weakens preschool performance. The family usually concentrates on many aspects of life, but not on their young children, which impacts the children's preschool performance and consequentially, their development.

With regard to the curriculum, Alshanwani (2013) conducted a study aimed at critiquing Self-Learning Curriculum according to criteria specified by the researcher. The family-school partnerships found that children's families were including the teachers' guideline only; while the other educational units lacked any family partnerships. However, I reviewed the curriculum and found a few mentions of school-community partnerships. For example, in the Friendship unit, the teacher invites two doctors in to show that friendship can be built from work life. Also, the only activity aimed at the community is in the My Country unit. The activity consisted of fundraising through selling products children create and then giving the money to charities or organizations that help people in need. Alsultan (2008) examined the reality of the collaboration between the local community and elementary, middle, and secondary schools in Riyadh City, Saudi Arabia. A random sampling of (842) principals showed that the relationships were weak. The researcher discovered many factors that impeded this collaboration, including restrictions imposed by the MoE. The collaboration activities were limited to inviting parents to school to discuss their children's academic achievement, and the schools never provided services for the community. Alshabrami (2005) investigated the relationships between the school and the local community and the results showed that schools highly benefited from the local community; however, their services provided to the community were weak. The community role in the family-school partnership has not reached its potential. Khalifa (2012) suggested a project for children's after-school programs. 
Her recommendation was based on the lack of these kinds of programs in Saudi Arabia, suggesting that if they are available, they are limited to a few activities. Therefore, the proposed program would provide a variety of after school activities for young children led by schoolteachers.

\section{Methodology}

\subsection{Study Sampling}

Unlike with quantitative research sampling, researchers are recommended to use the purposeful sampling procedure for qualitative research sampling. They "intentionally select individuals and sites to learn or understand the central phenomenon...that provides voice to individuals who may not be heard otherwise" (Creswell, 2012, p. 206). Maximal variation sampling is a purposeful sampling strategy in which the researcher samples cases or individuals that differ on some characteristic or trait (e.g., different age groups).This procedure requires [the researcher identifies] the characteristic and then[finds] sites or individuals that display different dimensions of that characteristic(Creswell, 2012, p. 208-209).After sending a survey describing the aim of the research and the interview, a total (42) teachers volunteered to participate in the research. The demographic analysis indicated that these teachers had different years of experience (1 to 10 and more than 10). A total of (12) teachers were purposefully selected among the (42) teachers. The criteria for recruiting teachers were to send text messages to all participants, and the teachers who responded first were chosen. The rest of the responding teachers were listed on a backup list. Therefore, as seen in Table (1), the total number of (12) teachers, four teachers in each Social economic area, was achieved. Four teachers were in each of the years of experiences category.

Table (1)

Study Participations

\begin{tabular}{|l|l|l|}
\hline Years of experience & Social Economic Area & Volunteered Teachers \\
\hline Fewer than 10 years & High & 2 \\
\hline More than 10 years & High & 2 \\
\hline Fewer than 10 years & Middle & 2 \\
\hline More than 10 years & Middle & 2 \\
\hline Fewer than 10 years & Low & 1 \\
\hline More than 10 years & Low & 3 \\
\hline Total & 12 \\
\hline
\end{tabular}

\subsection{Data Collection}

An approval of the institutional review board (IRB) at the University of Alabama at Birmingham was obtained, and American Psychological Association guidelines for ethical conducted in research were followed. The informed consent explained the study purpose, participation in the study was voluntary, and all information was used for study purposes only. Before the interview, an electronic participant recruitment letter was sent through Qualtrics to explain the purpose of the study to avoid deception and obtain their signed voluntary consent. The participants were given a pseudonym for use in in this research. The semi-structured interview questions were developed from previous research. The questions focused on teachers' experiences with the SPFC implementation obstacles in their preschools. Interviews were conducted individually by phone and to protect the teachers' privacy. They were conducted during Fall 2017, and each interview took (25-40) minutes.

\subsection{Data Analysis:}

Thematic analysis was used to analyze data. Nowell, Norris, White, and Moules, (2017) indicated that thematic analysis is used to reduce a large number of different perceptions and to create a more coherent account of the data. It helps the researcher to underline the similar experiences and distinguish the differences. Braun and Clarke (2006) explained the analysis steps:

1. Reading through the participants' transcripts to understand each experience.

2. Coding by writing notes near significant phrases in each transcript.

3. Clustering the codes to create themes and sub-themes.

4. Reviewing the codes and the themes for coherent assurance.

5. Deciding the themes and sub-themes' names.

6. Writing up the report. 


\subsection{Results:}

Thematic analysis identified two major themes: partnership obstacles and partnership enhancement. The first theme included four sub-themes and answered the first research question: The second theme, partnership enhancement, answered the second research question.

3.4.1 Partnership obstacles. During their teaching years, public preschool teachers experienced many barriers toward practicing one or more partnership practices. There are four sub-themes in this theme, namely time, lack of skills, administrative restrictions, and personal preference.

3.4.1.1 The firs sub-theme is the time barrier. All teachers in this study reported that a lack of time was one of the obstacles in involving mothers in school activities. The school hours in Riyadh City were from 7 a.m. until 12: 30 p.m. Teacher H3 said, the school day "is full of activities, so we barely have time to finish all of the planned activities." Teacher H3 added, "our school hours are short . . . about six hours . . . and limited for a specific program decided in advance ... I cannot-change any part without official reasons and principal approval." Also, the mothers' time is tight."Even if the school offers volunteering opportunities, many mothers cannot make it because of their restricted time. They have jobs or little babies at home," said Teacher M2.Teacher H3 indicated that, "when sending home activities, some mothers do not look at them. They say, "we do not have time to review the school homework." She explained, as a teacher, that "it took time to choose the best activities and copy them for children to take home, but I am disappointed when children return them as they go. I stopped that recently."

However, it is all about proprieties. When mothers understood the significant role of the home learning, they found time to improve their children's learning at home. Teacher L2 identified,

Some teachers find time to involve mothers, and many mothers participate when invited . . In my experience, I witnessed that mothers do not believe in the importance of preschool education, so they claimed they do not have time . .. I know many mothers have a hard time managing their houses. They work and have little babies, but they find time to visit the school when invited, review school letters, help their children to read every night, and send notes all the time.

3.4.1.2 The lack of required skills is the second sub-theme. Some teachers reported that they had not received the needed training or background regarding the SPFC during their years of preservice studies. The university early childhood programs do not provide family, school, and community partnership classes. Teacher L2 asserted that she had not taken "any course during my bachelor's degree talking about relationships with children's families." She continued with, "There were one or two classes about the role of the family in children's life and education." Teacher M1 added, "I do not remember any classes related to family involvement topics at all. The professors may have mentioned that when talking about children's disciplines." During field training, Teacher M2, noted, "As a preservice teacher, I was not allowed to contact families or attend any mother- teacher meeting or read letters from or to families." Teacher M2 specified that, "Honestly, I could not find the best way to communicate with mothers." Teacher L2 clarified,

You should contact the parents; this is so important for children's education, development . . . and behaviors. These phrases were mentioned in many classes, but no one told us how to do that. we made so many mistakes at the beginning. I wish there was a class or more related to family involvement.

For collaborating with the community skills, Teacher $\mathrm{H} 2$ stated,

We never heard about how to collaborate with the community during my studies in the university. In some classes, there were examples of how local agents may elevate children's learning like fire fighters, doctors . . . The official curriculum suggests examples, also. But I do not know how to invite them at the beginning of my career. Now things have gotten better, I learned from other teachers how and when to invite them.

In service teachers' experiences revealed the lack of in-service training related to SPFC. All the teachers documented they had never been offered or participated in workshops about the partnerships. Teacher H3 said that "it was not easy to write letters to mothers . . I do not know what to say and when . . . what is the best way and appropriate way to contact the mothers." Teacher H4 reported that she "had over 40 workshops in different topics but nothing about family or community partnerships." Teacher L3 added, "Some workshops discussed the need to include parents, especially with misbehaving children, but we never had a workshop about how to do that." Teacher L4 explained,

"All the workshops I participated in were about children's learning and development. I do not remember any of them being about family partnerships." Teacher M2 had a different experience, in that she "participated in some meetings 
about the importance of contacting families . . . but these meetings encourage teachers to collaborate with families only."

Also, the families should have specific skills to communicate effectively with teachers. The teachers, in this research, explained that the weak communication practice may lean partially on families' beliefs and skills. Teacher $\mathrm{H} 2$ said that Not all mothers have email. . . . One mother prefers to communicate via landline phone, but another wants printed copies of the memos.. . . Some text me when they need to communicate. . but the worst is the one who insists on coming in each time she needs to talk to me, ... which is not professional at all.

The teachers liked to use advanced technology to communicate with families. Yet, "when using emails, the classroom Facebook page, or an Instagram account to share newsletters, many mothers kept complaining that they wanted the oldfashioned ways" (Teacher M4). In this area, Teacher H2 expressed that It is a challenge that the teacher is supposed to communicate with all families in their suitable ways. Some prefer to learn news from social media, such as Twitter or Facebook, . . . but some want the traditional methods, and other mothers think such communication is unnecessary unless it is an emergency. Teacher L1 said, "Some mothers are busy at home or work and prefer not to communicate at all." Teacher H2 talked about her experience working with the community, in that "it was almost a personal effort to work with community services." For example, Teacher M4 noted, "The teacher or our principal contact... [business owners] or sometimes they send commercial offers, like foods companies. So, we receive the approval from the MoE and invite them."

3.4.1.3 Administrative restrictions are the third sub-theme. The bureaucratic central educational system in Saudi Arabia (which offers united instructions to all regions, monitors the implementation, and assigns authorities to higher positions) makes it hard to involve families or collaborate with the community. The teachers explained their lack of autonomy to become partners with families and the community; as Teacher M2 said, "We tried to visit factories or public libraries, but the MoE long and complicated process that is required to gain the approval prevents us." Teacher L2 explained her borders and role in the partnerships as:

It is not prohibited but complicated... We collaborate with many agencies such as hospitals, train stations, the public library, and so on... [Yet], as a teacher, I am not allowed to do that myself. My role is to suggest some local agencies, places, and activities to the school principal, and she decides what is the best and then sends to the supervision office to gain approval.

Teacher M1 indicated that "we receive regulations and memos from the MoE, and we must sign that prevents any outside party or individuals from participating in our program activities without gaining approval in advance from the [educational supervision] office." The school principal has the right, sometimes, to use practices. The MoEsends circulations to The Visiting Mothers Program and conduct workshops, but "they are not mandatory. The MoEsuggests, encourages, motivates... but there is no penalty if we do not use the programs" Teacher M1 continued, "I remember my previous principal kept these regulations in her office and we never knew about them..."

Regarding decision making, all the teacher asserted that their school or the MoE did not offer any opportunities to involve families in any decision-making groups. Teacher L1 said that "the curriculum was formed in advance... we just implement whatwe have." Teacher M3 added, "If I changed a little bit in the educational unit, the educational adviser will reject that... so how can we involve mothers to change the curriculum?". About the families' roles in making decisions, teachers indicated:

Mothers can make decisions regarding their children's behaviors or if they prefer to work with their children to improve their literacy and math skills... but we cannot involve them to alter the curriculum... the teachers themselves cannot do that... these decisions come from higher authorities (Teacher M4).

\section{Teacher H4 emphasized:}

From my experience, some teachers welcome mothers to make some decisions and others do not... for me, I have a group of mothers, and they assigned one to represent them... the voices were heard, and we made some decisions like activities in the classroom corners related to concepts I teach... I know that we cannot change something at the school level, but at least mothers are involved in my decisions... children gained the advantage that they have more enjoyable activities.

3.4.1.4 The fourth sub-theme is the personal preferences. Some teachers hold to the idea that family and community partnerships with school is significant at some points; however, this should be very limited and differs according to the family's performance. Teacher L3 claimed: 
Not all families are the same. I would use four classifications. Silent families are the most difficult because I do not know what they want. I try to communicate them, but they respond only weakly. Neglectful families are the least difficult; they do not care about the children and think that the preschool is a day care and that the teachers are nannies, so I only contact them for emergencies. Other families are very cautious and take care of their children. . . . We communicate with them frequently. The fourth are the aware families. These parents are educated and hold deep knowledge about nurturing. . . . It is hard or impossible to be involved with the first two types families. They ignore letters or notes. . . The third family type is sometimes hard to deal with. For example, a mother asked me how often her child coughs and what exactly she says to her classmates. They try to control their children's lives and environments everywhere, which is impossible. . . I I prefer to not work with them as much as I can. The aware family is the best. They know their limits and work with their children, not for them.

About the community, Teacher M3 noted that "children's safety comes first. I cannot invite someone to talk to the children unless I can trust him or her... I cannot take them outside the school building for any reason... It is my responsibility to keep them safe." The work environment served as a barrier to the partnerships. Even though the teachers were enthusiastic to work with families and the community, others discouraged them. "I feel that I am the only one who wants to work with families," Teacher L1 continued,

When discussing which workshop we can provide to the mothers, many teachers become annoyed and said 'do not open closed doors, we do not want to have extra work, mothers have not asked for workshops, or no one will participate.

Teacher M3 addressed the peer pressure: "The group of teachers I work with now are discouraging me. I feel disappointed when I give them my ideas and not one of them is interested." Teacher L4 explained, "in my first years of teaching, there was a teacher conducted workshop in different topics for mothers, like healthy foods; I like the idea and asked the principal, but she said that we do not have time for unnecessary things."

Without any rewards or encouragement, Teacher H3 said that "our school principal would not be interested to work toward the partnerships more than what is written in the school official curriculum." Teacher M1 explained:

I do not ignore the importance of the family involvement, but no one ask me to involve mothers other than in regular meetings or as needed... Even collaborating with community resources, the MoEs ends regulations for events to collaborate with some community resources, but if we have time, we would conduct them or we would not, because this is ... not included in our yearly report [evaluation].

As Teacher H2 noted, "Because there is nothing in return, I do not think we [the teachers] would apply all of the practices." According to her experience, Teacher L3 stated that "it will be time wasting if there is no reward, especially if the families do not believe in the importance of this collaborating."

Another concern raised was the limited consideration of the preschool role in the education system in Saudi Arabia. The teachers believed that "even we work very hard in these partnerships and prepare fantastic programs for families... we need family and community understanding of our hard work and for them to collaborate with us." (Teacher M1). Some families viewed the preschool "as a nursery and we [the teachers] as nannies; they have not given the communication any import" (Teacher L1). Teacher L3 revealed that "for some children, we never have met their mothers; the mothers explained their neglect by saying that their kids' education at this moment is not important; they just want the child to be used to the social life." Even in critical situations, teachers claimed that some mothers ignored communications: "When I call the mother to assign an appointment to discuss her child's misbehavior, they keep ignoring." (Teacher L3)

Additionally, some teachers indicated that they do not have the right to give their opinion to the mothers regarding nurturing their own children. "It is not easy to tell the mother what to do with her children" (Teacher H3). Teacher H4 added, "A mother told me that is not of my business... [because] she is the mother and she knows what is better for her child." During a workshop about children's sexual abuse, a mother said:

It is not professional to discuss these things with our kids they are still young...I am a mother for 25 years and do not need to tell me what to do to protect my children (Teacher M2).

\subsubsection{Partnerships enhancement.}

When teachers addressed their experiences, they followed them with valuable enhancement suggestions. The teachers' recommendations concentrated on two sub-themes: Organizational reformation and knowledge and skill improvement. 
3.4.2.1 The first sub-theme is the organizational reformation. All teachers revealed that the MoE kept sending administrative circulars emphasizing the significance of family partnership in children's learning and development but that "this is not mandatory, and there is no credit to teachers' collaboration with families." Teacher H3 continued, "There should be items in the teacher's performance evaluation sheet related to family involvement." Teachers also need support and encouragement from principals and supervisors "I recommend giving families chances to participate during teaching. We cannot do that without permission from the principal” (Teacher M2).

Many teachers thought that delegation of authorities would solve the problem; they "need to have control of many things... need to decide who, what, and when to invite mothers or any community member... I wish I could take my children to field trips without waiting months for approval" (Teacher L2).Preschool teachers hope to facilitate their job by decreasing MoE restrictions. Teacher $\mathrm{H} 2$ said that "teachers or at least school principals need to have the control over family school partnerships...even taking advantages of community resources, each principal can do that without waiting for a permission from a long administrative pyramid."

3.4.2.2 The second sub-theme is the knowledge and skill improvement. Preschool teachers believed that they needed strong backgrounds and training related to the SPFC. Teacher M4 explained that "pre-service teachers' programs have to include subjects related to family-school -relationships." Teacher M1 added:

The family-school or school-community topics must be in detail and in independent subjects... [that] discuss partnerships topics... and community resources. We need to know what the best resources are and how to communicate with community people and agencies to support and enhance teaching.

During the field training, which usually takes place during the last year in early childhood bachelor's programs, teachers are encouraged to "give [pre-service teachers] a chance to communicate with children's mothers as much as possible... and of course under classroom teachers' supervision" (Teacher M3).

Because team spirit or group effect is important for individuals, Teacher L2 noted that "special training, I mean in service training should be given to teachers all the time... some teacher's think this is not important and frustrate others." Teacher $\mathrm{H} 2$ had a suggestion:

Each teacher has to get tests to measure her enthusiasm degree... we do not want anyone to let us down when we are eager to work with families... team spirt is important, and there should be an action to increase our teamwork quality.

Teachers' skills and interests vary; therefore, identification of training helps to provide appropriate workshops. Teacher L4 said, "Instead of providing similar training to all teachers in the city, I suggest surveying teachers to assess their abilities and skills and then deciding the proper workshops." Teacher M4 claimed that "I think that we need to meet with other preschool teachers once a year at least to exchange experiences and learn from each other."

The teachers addressed the need to raise awareness of the importance of the preschool level among the community. The preschool level in the educational ladder is still counted as preschool. Teacher H1 said, "We need to share the knowledge of the importance of the preschool in future life." Teacher H3 added, "It is not a place to leave children when parents are busy. Parents should know that this place is important for children's whole development... so many children's behaviors issues ... were solved or improved when we worked with families." She continued, "I suggest including the preschool in the educational ladder" (Teacher H3).

Local community agencies and members would like to partner with schools, but they lack guidance. Teacher $\mathrm{H} 1$ added:

We always receive memos regarding community resources, but we do not know how and when to involve them... some instructions should be added, and the benefits...in contrast, the community members and business should know about us... many of them want to cooperate but do not know how.

\section{Discussion}

The teachers' stories revealed issues related to SPFC. For parenting practice. Some teachers expressed that parenting is fully the family's responsibility. Teacher $\mathrm{H} 4$ provided an example of a mother-teacher conflict: "A mother told me that is none of my business ... [because] she is the mother and she knows what is better for her child."

When the mother-teacher relationship is broken, children are the victims. Bronfenbrenner (1977)argued that children's development is influenced by various systems around them, including the mesosystem, which consists of interactions with those who are closest to the child: family members, teachers, and classmates. The unity of roles and goals between teachers and families is essential for children's healthy progress. Paquette and Ryan (2001) stated that, if the relationship between home and school breaks down, children's growth will be negatively affected. 
This study found that families varied in their intensity of communication. Some teachers explained that the neglected families do not communicate with schools because they view the preschool "as a nursery and we [the teachers] as nannies; they have not given communication any importance" (Teacher L1). Scholars documented the negative consequences of these weak relationships in many previous studies. For example, Ghahwaji (2007) stressed that many Saudi Arabian community members did not believe that the preschool period was significant, and this led them to see the teachers as babysitters. This false perception limited the efficacy of implementation aimed at early-childhood goals, according to Alotaibi and Alswelem (2002), who found that community members' lack of consideration of the preschool teachers' role made families uncooperative in terms of a lack of home-based learning and a deficient consideration of preschool's importance in children's lives; this was a significant component in preventing achievement of the educational goals. Albaiz (2009) found similar results: preschool principals noted that the parents' beliefs about the importance of early-childhood education affected these institutions' achievement of educational goals regarding children's development. This study revealed that not all families prefer using technology over traditional methods like hard-copy letters. Albaiz (2009) found that some families preferred traditional written, hard-copy communication methods. However, this method is obsolete and costly. The technological revolution has brought new media types such as text messages, emails, and social media applications.

The classical view of home-school partnerships in Saudi Arabia is that the family members help children to complete their homework or illustrate parts of an assignment task for elementary school children or upper but not for the preschool level. That is because the official preschool curriculum has not provided daily learning activities and takehome activities be teachers' suggestions. Research has shown that learning at home was considered a significant component in children's development. For example, Puglisi, et al. (2017) proved that home-based literacy activities promoted children's linguistic development. Concomitant with those benefits of home-learning activities,

Lack of time was one obstacle that hindered the communication between the teachers and the children's families. Teacher H3 said, "[the schedule] is full of activities, so I barely have time to finish all of the planned activities." Epstein et al. (2019) emphasized that home-school communication should be reciprocal. Yet, time restriction for both families and teachers prevent effective communication (Ingram, Wolfe, \& Lieberman, 2007). In Saudi Arabia, teachers are usually mothers and are responsible for their families. Once they arrive home, they practice their role as mother and have no time to follow up on work tasks such as communicating with students' families. The teachers in this study clarified that they have limited volunteering opportunities. Research found evidence that the lack of support from managers has weakened families' involvement in schools (Hourani et al., 2012). The most distinct volunteering practice was when mothers visited the classroom The Visiting MotherProgram. However, Epstein et.al, (2019) clarified that volunteering can be in or out of the school. In-school volunteering is wider than the mothers visiting and bringing gifts. It means to work voluntarily inside of the school building with teachers, school personnel, or other parents, such as monitoring children in playground or assistant teaching. For this reason, Burke (2001) emphasized that teachers have to assign plans for volunteering and not allow it to be arbitrary. If they do not, volunteering will produce negative consequences.

It appeared that the teacher preferred to not involve mothers during decision-making for their children. Some teachers explained that mothers can make decisions in conjunction with teachers regarding to their children's behaviors. According to the ecological system theory, conflict between the two parties, the family and the child's teacher, negatively influence a child's development (Paquette\& Ryan, 2001). The more welcoming a teacher is to engage the family in decision-making results in more successful children. Arguea and Conroy (2006) found in their study about parents' partnerships as decision-makers that the higher a parents' engagement in the decision-making process the better their students' schoolwork performance. On the other hand, some teachers believed that families were the children's first teachers; hearing families' opinions toward their child's learning and development increased the efficacy of teachers' work with children.

The relationships between teachers are also an issue. Some teachers in this study indicated that they suffered peer pressure and discouragement when they were excited to implement parenting practice. Bellemare, Lepage, and Shearer (2010) asserted in their empirical research that peer pressure decreased employees' productivity. Souto-Manning and Swick (2006), also; noted that specific school cultures influence teachers' beliefs about family involvement.

The teachers stated that their preparation, both during preservice year and before, was lacking in classes or trainings related to the SPFC - or any type of communication with families. Tichenor (1998) emphasized that working with families must be a major topic in preservice teaching programs so that preservice teachers have all the knowledge they need about the significance of the SPFC. Even collaboration with the community practice, the teachers expressed the lack of background onthis topic in their preservice studies. They asserted that, in their university years, there were no 
classes about building partnerships with the community. The current research researcher investigated in-service teachers' experiences with the community as well. Teachers' statements proved that community partners would like to collaborate, but they need organized invitations from a school or from the MoE.

This is addressed in SEDL (2000) agencies and members of the community will engage in school activities when invited. That is, schools ought to identify opportunities in the community and organize such work. School-community collaboration is not common in Saudi Arabia. Public preschools are free because the government bears the costs of education. Therefore, community members think that they are not supposed to collaborate with the schools. Because collaboration with the community is not included in the annual teachers' evaluation forms, which the educational supervisors use to assess teachers' performance, many are rather reluctant to work with the community. Sanders (2001) agreed with this result and noted that one of the obstacles preventing teachers from collaborating with the community is that those in the management level lack adequate training on partnerships with the community.

The teachers' statements disclosed two major areas of improvement: administrative reformation and teachers' skills improvement. For administrative reformation, the teachers affirmed that they received circulars from theMoE that were relevant to their partnerships with the children's families and the community; however, these partnerships were optional. Indeed, Epstein et al. (2019) found that, even though scholars have shown that partnerships with families and the community have brought significant results in terms of improving children's learning and development, schools and administrators give these partnerships inadequate attention. Linking teachers' professional functioning to external stimulation encourages those teachers to be more effective. Therefore, including the SPFC in the teachers' annual evaluation card is vital in ensuring that they implement the practices effectively.

Some teachers indicated that they are enthusiastic to work with families and the community. Prior knowledge about the SPFC is necessary, and the teachers who have missed this essential preparation must receive it during their career. The teachers in this study claimed that that they had not attended any workshops or received training related to the SPFC. Consequently, in-service teachers' programs are an important component of their professional performance improvement. Hoover-Dempsey et al. (2002) found that elementary- and middle-school teachers who attended programs related to family involvement enhanced their effectiveness when working with families. This efficacy also improved the teachers' ability to overcome family-involvement barriers.

Even once teachers have the required knowledge, they are unable to apply it to partnerships until they are given the authority to activate it. Scholars such as Alsultan (2008) have found that administrative restrictions are a barrier to the implementation of the SPFC. This study's results support this claim; the teachers in this study asserted that they needed permission from many parties before implementing the SPFC. The community comprises individuals and agencies that can provide valuable work for preschools as partners, but these entities need guidance. This finding coincided with the SEDL's (2000) suggestion that schools are responsible for sending invitations to the targeted community members and businesses to tell them about partnership methods.

\section{Conclusion and Recommendations}

The teachers' rich experience in teaching added deep clarification to the research results. The lists of obstacles and suggestions documented in this study will help administrators to overcome these barriers to achieve the preschool goals. Partnerships with families and the community should be part of the preservice teachers' preparation programs. In addition, in-service teachers need continued training to ensure that they are up to date on all the new SPFC strategies and practices. The study's results revealed that SPFC, such as forming relationships with families and the community, are not mandatory. The teachers' annual evaluation lacks any mention of these items. For this reason, not all teachers are eager to work on these partnerships. To enhance such partnerships, it is important to include items that measure and evaluate these partnerships in teachers' evaluations. The teachers in this study mentioned that written communication methods are old-fashioned, but some families still prefer using them instead of technological communication. Either way, the goal is to reach families and conduct partnerships with them; therefore, teachers must follow families' preferences as closely as possible. At the same time, they should introduce the benefits of the technological methods to the old-fashioned families and show how it can be an advantage in the family-school partnership.

The families and the community need more awareness that preschool is more than just babysitting children while their parents or guardians are working. The preschool offers a healthy environment for the whole child's development and learning. 


\section{References}

Albaiz, N. (2009). Evaluating the goals of kindergarten in Saudi Arabia. (Unpublished Master's Thesis) King Saud University, Saudi Arabia.

Alghamdi, A. A. (2016). Examining preschool teachers' subjective beliefs toward developmentally appropriate practices: A Saudi Arabian perspective, Retrieved from ProQuest Digital Dissertations.

Alshabrami, R. (2005). Primary school principles' roles in building relationships between their schools and the local community. (Unpublished doctoral dissertation). Sudan: Sudan University of Science and Technology.

Alshanwani, H. (2013). Analyze the self-learning curriculum of the kindergarten child in Saudi Arabia. Association of Modern Education, Vol (9).

Alsultan, F. (2008). The reality of cooperation between school and local community and the mechanisms necessary for its development in Riyadh City. Educational and psychological journal. 31. 83-122.

Alotaibi\&Alswelem (2002). Goals of early childhood education in Saudi Arabia. Research Center of College of Education. 2-60

Arguea, N. M., \& Conroy, S. J. (2006). The effect of parental involvement in parent teacher groups on student achievement. School Community Journal, 13(2), 119- 136.

Bąk-Średnicka, A. (2018). Foreign Language Teacher Education: School Placements as a Source of Knowledge about Parents as Partners in the Educational Process. International Journal of Progressive Education, 14(6), 51-60.

Bellemare, C., Lepage, P., \& Shearer, B. (2010). Peer pressure, incentives, and gender: An experimental analysis of motivation in the workplace. Labour Economics, 17(1), 276-283.

Braun, V., \& Clarke, V. (2006). Using thematic analysis in psychology. Qualitative research in psychology, 3(2), 77101.

Bronfenbrenner, U. (1977). Toward an experimental ecology of human development. American psychologist, 32(7), 513-531.

Bronfenbrenner, U. (1999). Environments in developmental perspective: Theoretical and operational models. In S. L. Friedman \& T. D. Wachs (Eds.), Measuring environment across the life span: Emerging methods and concepts (3-28.) Washington, DC, USA American Psychological Association.

Burke, M., A. (2001). Recruiting and using volunteers in meaningful ways in secondary schools. NASSP Bulletin, 85(627), 46-52.

Catone, K., Friedman, K., Potochnik, T., \& Thompson, J. (2014). Family Engagement and education. Providence, RI: Annenberg Institute for School Reform at Brown University.

Creswell, J. W. (2012). Educational research: Planning, conducting, and evaluating quantitative. Boston: Pearson.

Epstein, J. L. (1992). School and family partnerships. Report No. 6. Center on Families, Communities, Schools, and Children's Learning. Baltimore: Johns Hopkins University.

Epstein, J. L., \& Sanders, M. G. (2000). Connecting home, school, and community: New directions for social research. In M. T. Hallinan (Ed.), Handbook of the sociology of education (285-306). New York, NY: Kluwer Academic/Plenum Publishers.

Epstein, J. L., Sanders, M. G., Sheldon, S., Simon, B., Salinas, K., Van Voorhis, F. L., ...Williams (2009). School, family, and community partnerships: Your handbook for action. Thousand Oaks, CA: Corwin Press.

Epstein, J. L., Sanders, M. G., Sheldon, S. B., Simon, B. S., Salinas, K. C., Jansorn, N. R., \& Williams, K. J. (2019). School, family, and community partnerships: Your handbook for action (4th ed.). Thousand Oaks, CA: Corwin Press.

Flynn, G. V. (2007). Increasing parental involvement in our schools: The need to overcome obstacles, promote critical behaviors, and provide teacher training. Journal of College Teaching \& Learning (TLC), 4(2).

Ghahwaji, N. (2007). The status of preschool teachers in Saudi Arabia: Controversial and challenging concerns. International Conference on the Status of Muslim Women in Contemporary Societies: Realities and Prospects, International Institute for Muslim Unity. Kuala Lumpur: Malaysia.

Graham-Clay, S. (2005). Communicating with parents: Strategies for teachers. School Community Journal, 15(1), 117129.

Hakim, A. (2012). The Educational System and Its Policy. Egypt: Etrak publishing.

Hourani, R. B., Stringer, P., \& Baker, F. (2012). Constraints and subsequent limitations to parental involvement in primary schools in Abu Dhabi: Stakeholders' perspectives. School Community Journal, 22(2), 131-160.

Hoover-Dempsey, K. V., \& Walker, J. M. (2002). Family-school communication. A paper prepared for the Research Committee of the Metropolitan Nashville/Davidson County Board of Public Education, and made possible through a grant by The Frist Foundation. 
Ingram, M., Wolfe, R. B., \& Lieberman, J. M. (2007). The role of parents in high achieving schools serving lowincome, at-risk populations. Education and Urban Society, 39(4), 479-497.

Ishimaru, A. M. (2017). From family engagement to equitable collaboration. Education Policy, 78, 149-182.

Khalifa, H. (2012). After school programs for kids in Saudi Arabia. (Unpublished master's degree thesis). USA: Polytechnic institution of New York University.

Langdon, C. \& Vesper, N. (2000). The sixth Phi Delta Kappa poll of teachers' attitudes toward the public schools. Phi Delta Kappan, 81(8), 607-611.

Leddy, H. G. (2019). Involved minority parents enhance the quality of elementary school. Education Digest, 84(8), 5561.

Ministry of Education. (2014). The Self Learning Curriculum. Saudi Arabia.

Ministry of Education, (2019). The Organizational Guideline of The School Partnership with The Family and Community. Saudi Arabia

Noguera, P. A. (2001). Transforming urban schools through investments in the social capital of parents. In S. Saegart, J. P. Thompson, \& M. Warren (Eds.), Social capital and poor communities (189-212). New York, NY: Russell Sage.

Nowell, L. S., Norris, J. M., White, D. E., \&Moules, N. J. (2017). Thematic analysis: Striving to meet the trustworthiness criteria. International Journal of Qualitative Methods, 16(1).

Obeidat, O. M., \& Al-Hassan, S. M. (2009). School-parent-community partnerships: The experience of teachers who received the queen Rania award for excellence in education in the Hashemite Kingdom of Jordan. School Community Journal, 19(1), 119-135.

Olmstead, C. (2012). Using technology to increase parent involvement. Retrieved from ProQuest Digital Dissertations. (AAT 3486303)

Paquette, D., \& Ryan, D. P. J. (2001). Bronfenbrenner's ecological systems theory. Retrieved from: http://www.floridahealth.gov/AlternateSites/CMSKids/ providers/early_steps/training/documents/bronfenbrenners_ecological.pdf

Puglisi, M. L., Hulme, C., Hamilton, L. G., \&Snowling, M. J. (2017). The home literacy environment is a correlate, but perhaps not a cause, of variations in children's language and literacy development. Scientific Studies of Reading, (21)6. 498-514.

Saudi vision 2030. (2016). IRTIGAA. Retrieved from: http://vision2030.gov.sa/en

Sanders, M. G. (2001). The role of "community" in comprehensive school, family, and community partnership programs. The Elementary School Journal, 102(1), 19-34.

SEDL. (2000). Family and community involvement reaching out to diverse populations.

Schweiker-Marra, K. E. (2000). Changing teacher attitudes and actions to promote better parent-teacher communications. ERS Spectrum, 12-18.

Simon, B. S. (2001). Family involvement in high school: Predictors and effects. Nassp Bulletin, 85(627), 8-19.

Souto-Manning, M., \&Swick, K. J. (2006). Teachers' beliefs about parent and family involvement: Rethinking our family involvement paradigm. Early Childhood Education Journal, 34(2), 187-193.

Tatweer (2015). Saudi early learning standards (SELS). Retrieved from: https://kids.tatweer.edu.sa/

Tichenor, M. S. (1998). Preservice teachers' attitudes toward parent involvement: Implications for teacher education. The Teacher Educator, 33(4), 248-259.

The Detroit Community-Academic Urban Research Center. (2014). Parent engagement in school decision-making. Retrieved from: https://www.detroiturc.org/images/PDFs/6\%20

Walsh, B. A., Romo, G., \&Jeon, H.-J. (2018). Parental Perspectives on Transition to Kindergarten Videos to Promote Family Involvement. Early Childhood Education Journal, 46(6), 655-663 